\title{
Stability of an ophthalmic formulation of polyhexamethylene biguanide in gamma-sterilized and ethylene oxide sterilized low density polyethylene multidose eyedroppers
}

\author{
Yassine Bouattour $^{1}{ }^{\text {, }}$ Philip Chennell ${ }^{\text {Corresp., }}{ }^{2}$, Mathieu Wasiak ${ }^{1}$, Mireille Jouannet ${ }^{1}$, Valérie Sautou ${ }^{2}$ \\ ${ }^{1}$ CHU Clermont-Ferrand, Pôle Pharmacie, Clermont-Ferrand, France \\ 2 Université Clermont Auvergne, CHU Clermont-Ferrand, CNRS, SIGMA Clermont-Ferrand, ICCF, Clermont-Ferrand, France \\ Corresponding Author: Philip Chennell \\ Email address: pchennell@chu-clermontferrand.fr
}

Background: Polyhexamethylene biguanide (PHMB) eye drops are a frequently used medication to treat Acanthamoeba keratitis. In the absence of marketed PHMB eye drops, pharmacy compounding units are needed to prepare this much needed treatment, but the lack of validated PHMB stability data severely limits their conservation by imposing short expiration dates after preparation. In this study we aim to assess the physicochemical and microbiological stability of a $0.2 \mathrm{mg} / \mathrm{mL}$ PHMB eye drop formulation stored in two kinds of polyethylene bottles at two different temperatures.

Methods: A liquid chromatography coupled with diode array detector (LC-DAD) stability-indicating method was validated to quantify PHMB, using a cyanopropyl bonded phase (Agilent Zorbax Eclipse XDB$\mathrm{CN}$ column $4.6 \mathrm{~mm} \times 75 \mathrm{~mm}$ with particle size of $3.5 \mu \mathrm{m}$ ) and isocratic elution consisting of acetonitrile/deionized water (3/97 v/v) at a flow rate of $1.3 \mathrm{~mL} / \mathrm{min}$. PHMB eye drops stability was assessed for 90 days of storage at 5 and $25^{\circ} \mathrm{C}$ in ethylene oxide sterilized low density polyethylene (EOSLDPE) and gamma sterilized low density polyethylene (GS-LDPE) bottles. The following analyses: visual inspection, PHMB quantification and breakdown products (BP) screening, osmolality and $\mathrm{pH}$ measurements, and sterility assessment. PHMB quantification and BP screening was also performed on the drops emitted from the multidose eyedroppers to simulate in-use condition.

Results: The analytical method developed meets all the qualitative and quantitative criteria for validation with an acceptable accuracy and good linearity, and is stability-indicating. During 90 days of storage, no significant decrease of PHMB concentration was found compared to initial concentration in all stored PHMB eye drops. However, BP were found at day 30 and at day 90 of monitoring in both kind of bottles, stored at $5^{\circ}$ and $25^{\circ}$, respectively. Although no significant variation of osmolality was found and sterility was maintained during 90 days of monitoring, a significant decrease of pH in GS-LDPE PHMB eye drops was noticed reaching 4 and 4.6 at $25^{\circ} \mathrm{C}$ and $5{ }^{\circ} \mathrm{C}$ respectively, ompared to initial pH of 6.16.

Discussion: Although no significant decrease in PHMB concentration was found during 90 days of monitoring in all conditions, the appearance of breakdown products and their unknown toxicities let us believe that $0.2 \mathrm{mg} / \mathrm{mL}$ PHMB solution should be conserved for no longer than 60 days in EOS-LDPE bottles at $25^{\circ} \mathrm{C}$. 
1 STABILITY OF AN OPHTHALMIC FORMULATION OF POLYHEXAMETHYLENE BIGUANIDE IN GAMMA-STERILIZED AND ETHYLENE OXIDE STERILIZED LOW

6 Yassine Bouattour (1), Philip Chennell (2) *, Mathieu Wasiak ${ }^{(1)}$, Mireille Jouannet (1), Valérie Sautou $7 \quad(2)$

8 (1) CHU CLERMONT-FERRAND, PÔLE PHARMACIE, F-63000 CLERMONT-FERRAND, 9 FRANCE

(2) UNIVERSITÉ CLERMONT AUVERGNE, CHU CLERMONT FERRAND, CNRS, SIGMA

* : corresponding author:

Dr Philip Chennell, Hospital Pharmacist, PharmD MSc

pchennell@chu-clermontferrand.fr

Phone : +(33)4 73751036

17

CNRS UMR 6296 MPS

Institut de Chimie de Clermont-Ferrand (ICCF)

UFR de Médecine Pharmacie

Place Henri-Dunant, 63003 Clermont-Ferrand

FRANCE

23

24

25

26 


\section{STABILITY OF AN OPHTHALMIC FORMULATION OF POLYHEXAMETHYLENE BIGUANIDE IN GAMMA-STERILIZED AND ETHYLENE OXIDE STERILIZED LOW DENSITY POLYETHYLENE MULTIDOSE EYEDROPPERS}

\section{ABSTRACT}

BACKGROUND: Polyhexamethylene biguanide (PHMB) eye drops are a frequently used medication to treat Acanthamoeba keratitis. In the absence of marketed PHMB eye drops, pharmacycompounding units have to prepare this much needed treatment, but the lack of long-term validated PHMB stability data severely limits their conservation period by imposing short expiration dates after preparation. In this study we aim to assess the physicochemical and sterility of a $0.2 \mathrm{mg} / \mathrm{mL}$ PHMB eye drop formulation stored in two kinds of polyethylene bottles at two different temperatures.

METHOD: A liquid chromatography coupled with diode array detector (LC-DAD) stabilityindicating method was validated to quantify PHMB, using a cyanopropyl bonded phase (Agilent Zorbax Eclipse XDB-CN column $4.6 \mathrm{~mm} \times 75 \mathrm{~mm}$ with particle size of $3.5 \mu \mathrm{m}$ ) and isocratic elution consisting of acetonitrile/deionized water (3/97 v/v) at a flow rate of $1.3 \mathrm{~mL} / \mathrm{min}$. PHMB eye drops stability was assessed for 90 days of storage at 5 and $25^{\circ} \mathrm{C}$ in ethylene oxide sterilized low density polyethylene (EOS-LDPE) and gamma sterilized low density polyethylene (GS-LDPE) bottles. The following analyses were performed: visual inspection, PHMB quantification and breakdown products (BP) screening, osmolality and $\mathrm{pH}$ measurements, and sterility assessment. PHMB quantification and BP screening was also performed on the drops emitted from the multidose eyedroppers to simulate in-use condition.

RESULTS: The analytical method developed meets all the qualitative and quantitative criteria for validation with an acceptable accuracy and good linearity, thus is stability indicating. During 90 days of storage, no significant decrease of PHMB concentration was found compared to initial concentration in all stored PHMB eye drops. However, BP were found at day 30 and at day 90 of monitoring in both kind of bottles, stored at $5^{\circ}$ and $25^{\circ} \mathrm{C}$, respectively. Although no significant 
variation of osmolality was found and sterility was maintained during 90 days of monitoring, a significant decrease of $\mathrm{pH}$ in GS-LDPE PHMB eye drops was noticed reaching 4 and 4.6 at $25^{\circ} \mathrm{C}$ and $5^{\circ} \mathrm{C}$ respectively, compared to initial $\mathrm{pH}$ of 6.16 .

DISCUSSION: Although no significant decrease in PHMB concentration was found during 90 days of monitoring in all conditions, the appearance of breakdown products and their unknown toxicities let us believe that $0.2 \mathrm{mg} / \mathrm{mL}$ PHMB solution should be conserved for no longer than 60 days in EOSLDPE bottles at $25^{\circ} \mathrm{C}$.

\section{INTRODUCTION}

Acanthamoeba keratitis $(\mathrm{AK})$ is a rare but severe sight-threatening ocular infection with increasing prevalence worldwide. It is most common in contact lens (CL) wearers, with reported rates in the range of 1 to 33 cases per million CL wearers (Maycock \& Jayaswal, 2016). Patients with AK may experience pain with photophobia, ring-like stromal infiltrate, epithelial defect and lid oedema. If AK is not treated adequately and aggressively, it can lead to loss of vision (Lorenzo-Morales, Khan \& Walochnik, 2015). AK treatment must therefore be effective on both trophozoites and cyst stage of Acanthamoeba. Indeed, Acanthamoeba trophozoites are susceptible to antibiotics, antiseptics, antifungals, and antiprotozoals. However, due to the existence of a cyst form in Acanthamoeba that is highly resistant to therapy, this may lead to prolonged or resistant infections, as most of the above treatments remain ineffective. The first line treatments of $\mathrm{AK}$ are biguanides such as chlorhexidine or polyhexamethylene biguanide (Lorenzo-Morales, Khan \& Walochnik, 2015; Maycock \& Jayaswal, 2016). Polyhexamethylene biguanide, also known as Polyhexanide (PHMB) is a polymer used for its antiseptic and disinfectant properties. Its activity is due to interactions with the phospholipid membrane of the infectious cell, caused by rapid attraction of PHMB toward the negatively charged bacterial cell surface, with strong and specific adsorption to phosphate-containing compounds causing impairment of the integrity of the outer membrane. PHMB is then attracted to the inner membrane and bonded to phospholipids, with an increase in inner membrane permeability accompanied by bacteriostasis; complete loss of membrane function follows, with precipitation of intracellular constituents and a bactericidal effect (Broxton, Woodcock \& Gilbert, 1983; Ikeda, 
84 Tazuke \& Watanabe, 1983; Ikeda et al., 1984; Broxton et al., 1984). Due to this mechanism, PHMB is effective against numerous organisms like viruses such as HPV(Gentile, Gerli \& Di Renzo, 2012) or HIV (Krebs et al., 2008; Passic et al., 2010), Gram-negative and Gram-positive bacteria (Yanai et al., 2011), and fungi. In 1992, Larkin et al first reported the success of treating 5 of 6 patients with a $0.02 \%$ eye-drops of PHMB, qualifying the treatment as promising in this infection (Larkin, Kilvington \& Dart, 1992). A retrospective evaluation of the clinical outcomes of AK patients treated with unlicensed drugs, realized by the Community Research and Development Information Service (CORDIS), indicated that $96 \%$ of patients were using contact lenses, and that PHMB was the most frequently used medication. To treat AK, PHMB eye-drops are given hourly (day and night) for the first 48 hours before being reduced to hourly (daytime only) for several days or weeks. It is important that the treatment regimen is reduced and tailored to each clinical case to minimize any epithelial toxicity. The aim is to reduce therapy to 4 times a day, but patients may need to be on therapy for up to 6 months (Radford, Lehmann \& Dart, 1998)

The efficacy of PHMB established it as a promising candidate for obtaining an official AK treatment license by the European Medicines Agency (EMA) ("European Commission : CORDIS : Projects and Results : PHMB Eye drops for treating Acanthamoeba ocular infections"). A phase I study of PHMB eye-drops has already been completed and a phase III is still ongoing to demonstrate experimental scientific evidence on the quality, safety and efficacy of PHMB and to prepare the basis for a Marketing Authorization application. ("Polyhexamethylene Biguanide (PHMB) Ophthalmic Solution in Subjects Affected by Acanthamoeba Keratitis - Full Text View - ClinicalTrials.gov").

Until then, pharmacy-compounding units have to prepare PHMB eye-drops, but the lack of long-term validated PHMB stability data severely limits their conservation period by imposing short expiration dates after preparation.

The objective of this study was to assess the physicochemical stability and to control the sterility of a PHMB $0.2 \mathrm{mg} / \mathrm{mL}(0.02 \%)$ ophthalmic solution in two different low-density polyethylene multidose eyedropper, at two conservation conditions $\left(5^{\circ} \mathrm{C}\right.$ and $\left.25^{\circ} \mathrm{C}\right)$ for three months in unopened eyedroppers and during 10 hours of simulated patient use. 
113 Preparation and storage of PHMB solution formulations:

$114500 \mathrm{~mL}$ of $0.2 \mathrm{mg} / \mathrm{mL}$ solutions of PHMB were prepared by diluting $500 \mu \mathrm{L}$ of $200 \mathrm{mg} / \mathrm{mL}$ PHMB 115 solution (batch 15H28-B11, expiring September 2017, Fagron Services, Netherlands) in $49.5 \mathrm{~mL}$ of 116 deionized water (Versylene ${ }^{\circledR}$ Fresenius Kabi France, Louviers, France) to obtain a $2 \mathrm{mg} / \mathrm{ml}$ solution, 117 which was then diluted with $450 \mathrm{~mL}$ of sterile $0.9 \%$ Sodium chloride solution (Versylene ${ }^{\circledR}$ 118 Fresenius Kabi France, Louviers, France).

119 The solutions were sterilely distributed ( $2 \mathrm{~mL}$ per unit) using a sterile syringe tipped with a $0.22 \mu \mathrm{m}$ 120 pore size filter (reference SLGP033RS Millipore SAS batch number R5MA47234, Molsheim Cedex, 121 France) under the laminar air flow of an ISO 4.8 microbiological safety cabinet into two different 122 multidose low density polyethylene (LDPE) eyedroppers:

- 1) Gamma sterilized white opaque LDPE (GS-LDPE) eyedropper squeezable bottle (reference 10002134 with Novelia ${ }^{\circledR}$ caps reference 20050772, Nemera, La Verpillière Cedex, France)

- 2) Ethylene oxide sterilized white opaque LDPE (EOS-LDPE) eyedropper squeezable bottle

\section{Study design}

130

131

132

133

134

135

136

137

138

139

140

The stability of $0.2 \mathrm{mg} / \mathrm{mL}$ PHMB solution was studied in the two kinds of unopened multidose eyedroppers for 90 days at $25^{\circ} \mathrm{C}$ or $5^{\circ} \mathrm{C}$, and in simulated use conditions for 10 hours.

\section{Stability of $0.2 \mathrm{mg} / \mathrm{mL}$ PHMB solution in unopened multidose eyedroppers}

The eyedroppers containing PHMB were stored upwards at controlled refrigerated temperature (Whirlpool refrigerator) at $5^{\circ} \mathrm{C} \pm 3^{\circ} \mathrm{C}$ or in a climate chamber (BINDER GmbH, Tuttlingen, Germany) at $25^{\circ} \mathrm{C} \pm 2{ }^{\circ} \mathrm{C}$ and $60 \pm 5 \%$ residual humidity, until analysis.

Immediately after preparation, and at day 4, 8, 15, 30 and 90, 3 units per kind of eyedropper and storage temperature were subjected to the following analyses: visual inspection, PHMB quantification, breakdown products research, osmolality and $\mathrm{pH}$ measurements. Sterility was also assessed using 3 units for each kind of eyedropper and storage temperature immediately after preparation and after 30 and 90 days of storage. 
141 As a complementary study, $\mathrm{pH}$ monitoring of sodium chloride $0.9 \%$ solutions was also realized in

142 colored gamma sterilized LDPE bottle (Nemera ${ }^{\circledR}$ reference BW-F180), colored non-sterilized LDPE

143 bottles (Nemera ${ }^{\circledR}$ reference BW-F176), translucent non-sterilized LDPE bottles (Nemera ${ }^{\circledR}$ reference

144 BW-F178) and translucent non-sterilized polypropylene (PP) bottles (Nemera ${ }^{\circledR}$ reference

$145 \mathrm{C} 52116583658$ ), for 30 days, at $25^{\circ} \mathrm{C}$ and $60 \%$ residual humidity.

\section{Evaluation of PHMB concentrations in eye drops during simulated use.}

147 At day 0, 10 eyedroppers for each tested condition were subjected to simulated patient use: every 148 hour for 10 hours, a drop was emitted, and PHMB quantification was realized in 10 pooled drops of 149 the 10 bottles per conditioning and per storage temperature condition.

150

151 Analyses performed on the PHMB solutions

1520 Visual inspection

153 The multidose eyedroppers were emptied into polycarbonate test tubes and the PHMB solutions were 154 visually inspected under day light. Aspect and colour of the solutions were noted, and a screening for 155 visible particles, haziness, or gas development was performed.

156 PHMB quantification and breakdown products (BPs) research

\section{Chemicals and instrumentation}

158 For each unit, PHMB was quantified and breakdown products detected using a stability indicating 159 method adapted from Kusters et al (Küsters et al., 2013), by liquid chromatography (LC) using AS-

160

161

162

163

164

165

166

167 2055 Plus sampler with LG-1580-02 pump, Jasco MD-2018 plus with diode array detector in ultraviolet-visible range (DAD UV-Vis) and ChromNAV ${ }^{\circledR}$ software integrator (Jasco, France). The LC separation column used was an Agilent Zorbax Eclipse XDB-CN column $(4.6 \mathrm{~mm} \times 75 \mathrm{~mm})$ with particle size of $3.5 \mu \mathrm{m}$ and guard column $(4.6 \mathrm{~mm} \times 12.5 \mathrm{~mm})$. The mobile phase was an acetonitrile/ water mixture $(3 / 97 \% \mathrm{v} / \mathrm{v})$ in which the acetonitrile was HPLC quality (Chromosolv ${ }^{\circledR}$ for HPLC, Honeywell ${ }^{\circledR}$ ) and the water was deionized and sterile (Versylene ${ }^{\circledR}$ Fresenius Kabi France, Louviers, France). The flow rate through the column for the analysis was set at $1.3 \mathrm{~mL} / \mathrm{min}$, with the column thermo-regulated to a temperature of $25^{\circ} \mathrm{C}$. The injection volume was $100 \mu \mathrm{L}$. The quantification 
168 wavelength was set up at $220 \mathrm{~nm}$. Breakdown product (BP) detection was realized by screening with

169 DAD detector from $200 \mathrm{~nm}$ to $600 \mathrm{~nm}$.

\section{Validation method}

171 Linearity was initially verified by preparing one calibration curve daily for 3 days using 5 172 concentrations of PHMB 0.12;0.16;0.2;0.24 and $0.28 \mathrm{mg} / \mathrm{ml}$. Each calibration curve should have 173 determination coefficient $\mathrm{R}^{2}$ equal or higher than 0.999 . Homogeneity of the curves was verified using 174 Cochran test. ANOVA test was applied to determine applicability of linear model.

175 Each day for three days, 6 solutions of PHMB $0.2 \mathrm{mg} / \mathrm{ml}$ were prepared, analyzed and quantified 176 using a calibration curve prepared the same day. To verify the method precision, repeatability was 177 estimated by calculating RSD of intraday analysis and intermediate precision was evaluated using 178 RSD of inter-day analysis. Both RSDs should be less than 5\%. Specificity was assessed by comparing UV spectra using DAD detector. Method accuracy was verified by evaluating recovery of 5 theoretical concentrations to experimental values found using mean curve equation, and results should be found within the range of 95-105\%. Limit of detection (LOD) and limit of quantification (LOQ) were estimated based on the standard deviation of the response and the slope, following ICH guidelines. For 3 days, LOD was verified based on visual inspection of the chromatograms of 6 samples and LOQ was verified by calculating repeatability and trueness of measurement on 10 samples.

In order to exclude potential interference of degradation products with PHMB quantification, PHMB $0.2 \mathrm{mg} / \mathrm{mL}$ solutions was subjected to many forced degradation conditions. Degradation conditions were the following: $0.5 \mathrm{~N}$ hydrochloric acid for 30 minutes at $80^{\circ} \mathrm{C}, 0.5 \mathrm{~N}$ sodium hydroxide for 120 minutes at $80^{\circ} \mathrm{C}, 3 \%$ hydrogen peroxide at $80^{\circ} \mathrm{C}$ for 24 hours and thermal degradation for 24 hours at $80^{\circ} \mathrm{C}$. Susceptibility to light was not performed due to use of opaque bottles because of known photostability of PHMB (Roth et al., 2011)

\section{Osmolality and $\mathrm{pH}$ measurements}

For each unit, $\mathrm{pH}$ was measured using a SevenMulti TH S40 - Mettler Toledo pH-meter equipped with InLab ${ }^{\circledR}$ Micro Pro $\mathrm{pH}$ electrode. Measures were preceded and followed by instrument validation using standard buffer solution of pH 4 (HANNAH® Instrument). 
196 Osmolality was measured for each solution using an osmometer Model 2020 Osmometer ${ }^{\circledR}$

197 (Advanced instruments Inc, Radiometer, SAS, Neuilly Plaisance).

198 Sterility assay

199 Sterility test method was validated (i.e. growth promotion test, validation of the sterility assay and 200 elimination of the inhibitory effect) by Thibert et al. (Thibert et al., 2014), using a method adapted 201 from the European Pharmacopoeia sterility assay (2.6.1). Multidose eyedroppers were opened under 202 the laminar air flow of an ISO 4.8 microbiological safety cabinet, and the contents filtered under 203 vacuum using a Nalgene analytical test filter funnel onto a $47 \mathrm{~mm}$ diameter cellulose nitrate membrane 204 with a pore size of $0.45 \mu \mathrm{m}$ (ref 147-0045, Thermo Scientific, Thermo Electron SAS, Courtaboeuf 205 Cedex, France). The membranes were then rinsed with $90 \mathrm{~mL}$ of Letheen broth (VWR International, 206 Pessac, France), to remove any antibacterial effect of the solution and divided into two equal parts. 207 Each individual part was transferred to each of a fluid thioglycolate and soya tripcase medium, and 208 incubated at $30-35^{\circ} \mathrm{C}$ or $20-25^{\circ} \mathrm{C}$ respectively, for 14 days. The culture medium was then examined 209 for colonies.

\section{Data analysis - acceptability criteria}

211 The stability of diluted PHMB solutions was assessed using the following parameters: visual aspect 212 of the solution, PHMB concentration, presence or absence of breakdown products, $\mathrm{pH}$ and osmolality.

213 The study was conducted following methodological guidelines issued by the International Conference 214 on Harmonisation for stability studies (ICH guidelines for stability ("International Conference of 215 Harmonization (ICH), Quality Guidelines : ICH. Guidelines for stability Q1A to Q1f, (n.d.).”) (“ICH 216 Q5C: quality of biotechnological products: Stability testing of biotechnological/biological 217 products"), and recommendations issued by the French Society of Clinical Pharmacy (SFPC) and the

218 Evaluation and Research Group on Protection in Controlled Atmosphere (GERPAC)(“French Society 219 of Clinical Pharmacy (SFPC), Evaluation and Research Group on Protection in Controlled Atmospher 220 (GERPAC), Methodological guidelines for stability studies of pharmaceutical preparations, 2013.”). 221 A variation of concentration outside the $90 \%$ - $110 \%$ range of initial concentration (including the 222 limits of a 95\% confidence interval of the measures) was considered as being a sign of instability. 223 Presence of breakdown products and the variation of the physicochemical parameters were also 224 considered a sign of PHMB instability. The observed solutions must be limpid, of unchanged colour, 
225 and clear of visible signs of haziness or precipitation. Since there are no standards that define 226 acceptable $\mathrm{pH}$ or osmolality variation, $\mathrm{pH}$ measures were considered to be acceptable if they did not 227 vary by more than one $\mathrm{pH}$ unit from initial value ("French Society of Clinical Pharmacy (SFPC), 228 Evaluation and Research Group on Protection in Controlled Atmospher (GERPAC), Methodological guidelines for stability studies of pharmaceutical preparations, 2013.”), and osmolality results were interpreted considering clinical tolerance of the preparation.

\section{$\underline{\text { RESULTS }}$}

\section{PHMB quantification and breakdown products research}

234 PHMB retention time was of 9.1 minutes \pm 0.8 minute. The chromatographic method used was found linear for concentrations ranging from 0.12 to $0.28 \mathrm{mg} / \mathrm{mL}$ with a determination coefficient $\mathrm{R}^{2}$ equal or higher to 0.999 . Average regression equation was $\mathrm{y}=3985934.2 \mathrm{x}-12276.9$ where $\mathrm{x}$ is the PHMB concentration and $y$ the surface area of the corresponding peak. Interception was not significantly different from zero and average determination coefficient $\mathrm{R}^{2}$ of 3 calibration curves was 0.988 . Recovery of $0.2 \mathrm{mg} / \mathrm{mL}$ was $98.85 \pm 0.005$, repeatability's relative standard deviation (RSD) was $2.2 \%$ and intermediate precision's RSD was 3\%. LOD was equal to $0.021 \mathrm{mg} / \mathrm{mL}$ and LOQ was 0.065 $\mathrm{mg} / \mathrm{mL}$, and found within the range of linearity of the calibration curve with recovery coefficients of

242 less than $5 \%$.

243 Three impurities were found to be already present in the PHMB solution, two of them being visible only at $200 \mathrm{~nm}$ and with diode array detection, showing retention times of 3.0, 3.5 and $7.7 \mathrm{~min}$ on reference chromatograms and relative retention time of $0.32 ; 0.38$ and 0.84 compared to PHMB peak (Figure 1). At $200 \mathrm{~nm}$, the area of impurities 1 and 3 represented respectively $0.51 \%$, and $1 \%$ of PHMB peak area whereas only impurity 2 was visible at $220 \mathrm{~nm}$, representing $0.68 \%$ of PHMB peak surface.

After forced degradation (Figure 2), several breakdown products were detected with a resolution higher than 1.5 of PHMB peak to all its breakdown products, except for thermal degradation which showed no change in chromatograms after 24 hours of heating at $80^{\circ} \mathrm{C}$. Figure 3 summarises relative 
253 retention times and intensities of all detected impurities and breakdown products function of the

254 degradation conditions.

\section{Stability of PHMB in unopened multidose eyedroppers}

256 Physical stability:

257 All samples stayed limpid and uncoloured during the study, for both tested concentrations and 258 conservation temperatures, and there was no appearance of any visible particulate matter, haziness or 259 gas development.

260 Chemical stability

261 Throughout the dosage times, mean concentrations of PHMB in all studied conditions did not vary 262 by more than $5.2 \%$ of mean initial concentration (see Table 1 ).

263 Chromatographs showed no sign of breakdown products until day 60 included for both types of LDPE 264 eyedroppers at $25^{\circ} \mathrm{C}$. After 90 days of storage, many breakdown products appeared including a 265 breakdown product which had not been detected during forced degradation, with a retention time of $2662.5 \mathrm{~min}$. An increase in intensity of the acid breakdown product (retention time $1.5 \mathrm{~min}$ ), was also 267 noted for GS-LDPE bottles but not for EOS-LDPE bottles (Figure 4). When stored at $5^{\circ} \mathrm{C}$, another 268 previously undetected breakdown product with a maximum of absorbance at $280 \mathrm{~nm}$, appeared after 26930 days, for both LDPE eyedroppers (Figure 5)

271 Throughout the study, osmolality did not vary by more than $1.94 \%$ ( $5 \mathrm{mosm} / \mathrm{kg}$ ) of initial osmolality $272(258 \mathrm{mosm} / \mathrm{kg})$ for both types of LDPE eyedroppers at both storage temperatures.

273 For the PHMB kept in EOS-LDPE, pH did not vary throughout the study by more than 0.52 and 0.46 $274 \mathrm{pH}$ units from initial $\mathrm{pH}(6.27)$ when stored at $5^{\circ} \mathrm{C}$ and $25^{\circ} \mathrm{C}$ respectively. However, the $\mathrm{pH}$ decreased 275 considerably in the solutions conditioned in GS-LDPE, losing respectively 1.56 and $2.16 \mathrm{pH}$ units 276 from initial $\mathrm{pH}(6.16)$ after 90 days when stored at respectively $5^{\circ} \mathrm{C}$ and $25^{\circ} \mathrm{C}$ (see Figure 6). 
278 Figure 7 shows no significant decrease of non-colored non-sterilized PP bottle and colored and non279 colored non-sterilized LDPE bottle. However, we found a major decrease of $\mathrm{pH}$ (over 2.1 unit) after 28030 days in colored gamma sterilized LDPE bottle.

281

2820

283

284

285

\section{Stability of PHMB in simulated use conditions}

287

$\underline{\text { Sterility assay }}$ any signs of microbial growth. for any of the studied conditions, as presented in Table 2.

\section{DISCUSSION}

None of the 3 analysed solutions conserved in unopened bottles at day 0, day 30 or day 90 showed

During 10 hours of drop sampling, no variation exceeding of $\pm 10 \%$ of initial concentration was found

Our study presents new data on the physicochemical stability of an aqueous formulation of PHMB conditioned in two differently sterilized LDPE eyedroppers (gamma radiations and ethylene oxide). Our study also highlighted the influence of the mode of sterilization of the eyedroppers on the properties of the solutions they are designed to contain, as well as identifying a surprising chemical degradation of PHMB when conserved in refrigerated conditions.

Initial chromatograms of PHMB $0.2 \mathrm{mg} / \mathrm{mL}$ showed the presence of three impurities, which is in accordance with the analysis certificate of the raw material, which reports the presence of four impurities, one of which (hexamethylendiamine) is not visible in UV (Pubchem). PHMB retention time presented variabilities with an RSD of $8.8 \%$ due to the high sensibility of the method to minute acetonitrile concentration variation. The use of DAD detector added more specificity to the method and allowed the identification of PHMB during analyses despite the slight variations of retention time. Forced degradation assays showed that PHMB remained stable against most tested stress conditions except acidity. In fact, we found that PHMB concentration decrease was of about $28 \%$ after 15 min 
304 in $0.5 \mathrm{~N}$ of hydrochloric acid at $80^{\circ} \mathrm{C}, 20.2 \%$ after $120 \mathrm{~min}$ in $0.5 \mathrm{~N}$ of $\mathrm{NaOH}$ solution at $80^{\circ} \mathrm{C}$ and $30512.3 \%$ after 24 hours in $3 \%$ solution of hydrogen peroxide at $80^{\circ} \mathrm{C}$. On the other hand, $\mathrm{PHMB}$ 306 decrease was only of $2 \%$ after $24 \mathrm{~h}$ of heating at $80^{\circ} \mathrm{C}$ showing a resistance towards heating. All 307 breakdown products appeared during forced degradation were sufficiently separated from PHMB 308 peak with a resolution higher than 1.5. Since it was impossible to quantify breakdown products and 309 impurities, we estimated the relative absorbance of those products compared to PHMB peak. All of the products have a relative absorbance between $0,4 \%$ and $5 \%$, except for alkaline condition which showed two breakdown products of $68 \%$ and $118 \%$, suggesting that those breakdown products have a higher molar extinction coefficient than PHMB.

313 During three months of monitoring, mean concentration of PHMB remained within a $90-110 \%$ range of initial concentration in EOS-LDPE and GS-LDPE bottles, at 5 and $25^{\circ} \mathrm{C}$. In fact, all the analysed solutions showed a decrease of less than $6 \%$ at the end of the study. However, variability of PHMB concentrations was noticed during monitoring, causing enlargement of confidence interval in EOSLDPE eye-drops stored at $5^{\circ} \mathrm{C}$, and in GS-LDPE stored at 5 and $25^{\circ} \mathrm{C}$, possibly suggesting the beginning of an instability of the drug at these conditions. Only PHMB solution in EOS-LDPE bottles stored at $25^{\circ} \mathrm{C}$ stayed within the 90 to $110 \%$ of initial concentration range, when considering the $95 \%$ confidence interval. Breakdown products began to appear at day 30 for solutions stored at $5^{\circ} \mathrm{C}$ in both kind of bottles. Such results have not been reported in any research, but concurring information was found in the certificate of analyses of PHMB 20\%, suggesting that solution storage should be at a temperature higher than $8^{\circ} \mathrm{C}$. Eye-drops stored at $25^{\circ} \mathrm{C}$ showed the appearance of several breakdown products at day 90 of monitoring for both kind of bottles as well, demonstrating that PHMB is chemically more stable at $25^{\circ} \mathrm{C}$ than at $5^{\circ} \mathrm{C}$.

Although visual aspect was found unchanged and osmolality did not vary during the 90 days of monitoring in both conditioning at both temperatures, $\mathrm{pH}$ on the other hand presented a remarkable decrease during conservation in GS-LDPE bottles at 5 and $25^{\circ} \mathrm{C}$. In fact, we found that $\mathrm{pH}$ decreased from 6.16 to reach 4 and 4.6 at $25^{\circ} \mathrm{C}$ and $5{ }^{\circ} \mathrm{C}$ respectively in GS-LDPE bottles, but no significant variation noticed for EOS-LDPE. Gamma rays are energetic rays that oxidise LDPE, and could result in liberation of protons that could acidify contained solution. To further verify the cause of $\mathrm{pH}$ decrease (LDPE, LDPE dye, LDPE method of sterilisation or the PHMB solution itself), $\mathrm{pH}$ comparison of $0.9 \%$ sodium chloride solution conditioned in sterilized colored, non-sterilized colored 
334 and non-colored LDPE bottles, and uncolored non-sterilized PP bottles was realised as well. $\mathrm{pH}$ 335 comparison demonstrated that gamma sterilised eyedroppers were at risk of a $\mathrm{pH}$ decrease in sodium 336 chloride solution and thus could explain $\mathrm{pH}$ decrease in PHMB solution. This is probably due to 337 liberation of acids from LDPE when sterilized with gamma irradiation. In fact, Kawamura 338 (Kawamura, 2004) reported that acids such acetic acid, propionic acid, butanoic acid, pentanoic acid and acetone were detected in polyethylene and polypropylene products after irradiation doses of 10 , 30 and $50 \mathrm{kGy}$.

Six BPs was found at day 90 in both kind of LDPE eye drop bottles, among which one BP was not found in any condition during forced degradation assay, and another found in acid degradation conditions. The acid BP peak was very close to the solvent front peak which makes it difficult to quantify, but by comparing the intensity of this peak between solution in GS-LDPE and EOS-LDPE, we found that this peak was higher in GS-LDPE solution, which suggest that its formation was accelerated due to the acidification of the solution in GS-LDPE bottle. Since best stability of PHMB is between 5 to 7 (Küsters et al., 2013), the acidification of the solution in GS-LDPE could therefore accelerate its degradation.

PHMB eye drops was described to be stable for 45 days when frozen and for 14 days when refrigerated if prepared with $0.01 \%$ benzalkonium chloride water (McElhiney, 2013). The difference between stabilities of those eye drops to ours could be explained by the use of different excipient, since we used $0.9 \%$ sodium chloride instead, considered as more isotonic, or alternatively the study was not performed for a longer time. Despite there being no other published data on ophthalmic formulations of PHMB, its stability was assessed in other pharmaceutical forms. For instance, Lucas et al found that PHMB at $1 \mathrm{ppm}$ in multipurpose contact lens solution being stable after 30 days stored at $-20^{\circ} \mathrm{C}, 5^{\circ} \mathrm{C}$ and $25^{\circ} \mathrm{C}$ (Lucas, Gordon \& Stratmeyer, 2009). However, since their quantification method were not stability indicating, it is hard to confirm the absence of potentially toxic breakdown product in PHMB solutions. On the other hand, Küsters et al (Küsters et al., 2013) also found PHMB at $0.02 \%$ stable for 12 months at $22^{\circ} \mathrm{C}$ in wound gel and irrigation solution, but as previously mentioned, their method might not have been optimal for the detection of specific breakdown products and the galenic form of their product does not make it suitable for eye delivery. study at $25^{\circ} \mathrm{C}$ for up to 2 months without any detectable breakdown products appearing or other 
364 parameter modification when stored in ethylene oxide sterilized low density polyethylene bottles.

365 This information is therefore in favour of identical quality of the product after 60 days of storage. A 366 study of PHMB biological activity, using bioassays such as MIC testing or time-kills against standard

367 bacterial isolates or the use of an Acanthamoeba complete-kill assay (Kowalski et al., 2013) could 368 however confirm this information: as intact PHMB already possessed antimicrobial activity, 369 unchanged PHMB should retain this activity. Such an additional study could however be used to 370 investigate the activity of physicochemically unstable PHMB solutions. For example, when 371 breakdown products are observed, is the formulation still potent? Do these products or other 372 compounds released from the container modify PHMB activity or affect ophthalmic tolerance? This 373 investigation could therefore be coupled to a cytotoxicity study evaluating "unstable" formulation, in 374 order to assess the pertinence of the stringent quality specifications adopted for stability studies.

375 The sterility assay performed in our work followed the European Pharmacopeia sterility monography 376 (“Council of Europe, European pharmacopoeia, 2014. Monographs No. 2.6.1, eighth ed. Council of 377 Europe, Strasbourg") and did not reveal any microbial contamination after 3 months of storage. 378 Absence of microbiological growth during use is fundamental to improve patient safety. Optimal 379 microbiological sterility can be achieved using single dose eyedroppers, however such a technology 380 is not always applicable for all drugs or formulations and not available in most of hospital 381 compounding department.

382 During simulated use of PHMB eye droppers, we evaluated PHMB concentrations in emitted eye 383 drops for 10 hours, in order to research any sorption phenomenon that could lead to a decrease of

384

385

386

387

388

389

390

391

392 PHMB concentration in the delivered drops. Since PHMB eye drops must be taken each hour for the first 24 hours, any loss of PHMB concentration during use may probably delay healing. Any sorption phenomenon that could have happened would have appeared early, so the absence of any concentration decrease leads us to believe that no clinically relevant sorption happened. In our experiments, we pooled 10 drops for analytical reasons. We found no significant variation of PHMB concentration in both LDPE bottles, especially for GS-LDPE which contain silicone in their caps, thus establishing that there is no clinically significant sorption between PHMB and the used eyedroppers.

\section{CONCLUSION:}


393 Although no significant decrease in PHMB concentration was found during 90 days of monitoring, 394 the appearance of breakdown products and their unknown toxicities let us believe that $0.2 \mathrm{mg} / \mathrm{mL}$ 395 PHMB solution should be conserved for no longer than 60 days in EOS-LDPE bottles at $25^{\circ} \mathrm{C}$.

396

397 398

\section{REFERENCES:}

Broxton P., Woodcock PM., Gilbert P. 1983. A study of the antibacterial activity of some polyhexamethylene biguanides towards Escherichia coli ATCC 8739. The Journal of Applied Bacteriology 54:345-353.

Broxton P., Woodcock PM., Heatley F., Gilbert P. 1984. Interaction of some polyhexamethylene biguanides and membrane phospholipids in Escherichia coli. The Journal of Applied Bacteriology 57:115-124.

Council of Europe, European pharmacopoeia, 2014. Monographs No. 2.6.1, eighth ed. Council of Europe, Strasbourg

European Commission : CORDIS : Projects and Results : PHMB Eye drops for treating Acanthamoeba ocular infections. Available at http://cordis.europa.eu/result/rcn/159866_en.html (accessed October 22, 2017).

French Society of Clinical Pharmacy (SFPC), Evaluation and Research Group on Protection in Controlled Atmospher (GERPAC), Methodological guidelines for stability studies of pharmaceutical preparations, 2013. Available at http://sfpc.eu/fr/publicationsfr/documents-publies-par-la-sfpc/stabilite-des-preparations.html (accessed December 25, 2017). 
413 Gentile A., Gerli S., Di Renzo GC. 2012. A new non-invasive approach based on

414

415

416

417

418

419

420

421

422

423

424

425

426

427

428

429

430

431

432

433

434

435

polyhexamethylene biguanide increases the regression rate of HPV infection. $B M C$ Clinical Pathology 12:17. DOI: 10.1186/1472-6890-12-17.

ICH Q5C : quality of biotechnological products : Stability testing of biotechnological/biological products. Available at http://www.ich.org/products/guidelines/quality/article/qualityguidelines.html (accessed December 25, 2017).

Ikeda T., Ledwith A., Bamford CH., Hann RA. 1984. Interaction of a polymeric biguanide biocide with phospholipid membranes. Biochimica Et Biophysica Acta 769:57-66.

Ikeda T., Tazuke S., Watanabe M. 1983. Interaction of biologically active molecules with phospholipid membranes. I. Fluorescence depolarization studies on the effect of polymeric biocide bearing biguanide groups in the main chain. Biochimica Et Biophysica Acta 735:380-386.

International Conference of Harmonization (ICH), Quality Guidelines : ICH. Guidelines for stability Q1A to Q1f, (n.d.). Available at http://www.ich.org/products/guidelines/quality/article/qualityguidelines.htmlhttp://www.ich.org/products/guidelines/\%20quality/article/qualityguidelines.html (accessed January 4, 2016). (accessed December 25, 2017).

Kawamura Y. 2004. Effects of Gamma Irradiation on Polyethylene, Polypropylene, and Polystyrene. In: Irradiation of Food and Packaging. ACS Symposium Series. American Chemical Society, 262-276.

Kowalski RP., Abdel Aziz S., Romanowski EG., Shanks RQ., Nau AC., Raju LV. 2013. Development of a Practical Complete-Kill Assay to Evaluate Anti-Acanthamoeba Drugs. JAMA ophthalmology 131:1459-1462. DOI: 10.1001/jamaophthalmol.2013.5062. 
436 Krebs FC., Miller SR., Ferguson ML., Labib M., Rando RF., Wigdahl B. 2008. Polybiguanides,

437

438

439

440

441

442

443

444

445

446

447

448

449

450

451

452

453

454

455

456

457

458 particularly polyethylene hexamethylene biguanide, have activity against human immunodeficiency virus type 1. /data/revues/07533322/00590008/05001630/.

Küsters M., Beyer S., Kutscher S., Schlesinger H., Gerhartz M. 2013. Rapid, simple and stability-indicating determination of polyhexamethylene biguanide in liquid and gel-like dosage forms by liquid chromatography with diode-array detection. Journal of Pharmaceutical Analysis 3:408-414. DOI: 10.1016/j.jpha.2013.02.007.

Larkin DF., Kilvington S., Dart JK. 1992. Treatment of Acanthamoeba keratitis with polyhexamethylene biguanide. Ophthalmology 99:185-191.

Lorenzo-Morales J., Khan NA., Walochnik J. 2015. An update on Acanthamoeba keratitis: diagnosis, pathogenesis and treatment. Parasite 22. DOI: 10.1051/parasite/2015010.

Lucas AD., Gordon EA., Stratmeyer ME. 2009. Analysis of polyhexamethylene biguanide in multipurpose contact lens solutions. Talanta 80:1016-1019. DOI: 10.1016/j.talanta.2009.07.031.

Maycock NJR., Jayaswal R. 2016. Update on Acanthamoeba Keratitis: Diagnosis, Treatment, and Outcomes. Cornea 35:713-720. DOI: 10.1097/ICO.0000000000000804.

McElhiney LF. 2013. Compounding Guide for Ophthalmic Preparations. American Pharmacists Association.

Passic SR., Ferguson ML., Catalone BJ., Kish-Catalone T., Kholodovych V., Zhu W., Welsh W., Rando R., Howett MK., Wigdahl B., Labib M., Krebs FC. 2010. Structure-activity relationships of polybiguanides with activity against human immunodeficiency virus type 1. Biomedicine \& Pharmacotherapy = Biomedecine \& Pharmacotherapie 64:723-732. DOI: 10.1016/j.biopha.2010.10.001. 
459 Polyhexamethylene Biguanide (PHMB) Ophthalmic Solution in Subjects Affected by

460 Acanthamoeba Keratitis - Full Text View - ClinicalTrials.gov. Available at

461 https://clinicaltrials.gov/ct2/show/NCT03274895 (accessed October 22, 2017).

462 Pubchem.1,6-Hexanediamine. Available at https://pubchem.ncbi.nlm.nih.gov/compound/16402 (accessed December 25, 2017).

464

Radford C., Lehmann O., Dart J. 1998. Acanthamoeba keratitis: multicentre survey in England 465 1992-6. The British Journal of Ophthalmology 82:1387-1392.

466

467

468

469

470

471

472

473

474

475

Roth B., Hotz D., Mayer D., Läuchli S., Traber J. 2011. [Recommendations for the use of polyhexanide-containing products for the treatment of wounds]. Praxis 100:531-537. DOI: $10.1024 / 1661-8157 / \mathrm{a} 000517$.

Thibert E., Saliege M., Chapelle FA., Jouannet M., Traore O., Sautou V. 2014. Essai de stérilité des préparations ophtalmiques sur milieu Reasoner's agar no 2 (R2A) : une solution pour diminuer le temps d'incubation. Le Pharmacien Hospitalier et Clinicien 49:197-203. DOI: $10.1016 /$ j.phclin.2013.08.004.

Yanai R., Ueda K., Nishida T., Toyohara M., Mori O. 2011. Effects of ionic and surfactant agents on the antimicrobial activity of polyhexamethylene biguanide. Eye \& Contact Lens 37:85-89. DOI: 10.1097/ICL.0b013e31820cebc3. 


\section{Figure 1}

Reference chromatograms of $0.2 \mathrm{mg} / \mathrm{ml}$ PHMB solution. A: at $220 \mathrm{~nm}$; B: at $200 \mathrm{~nm}$ and $\mathrm{C}$ : diode array detection screening

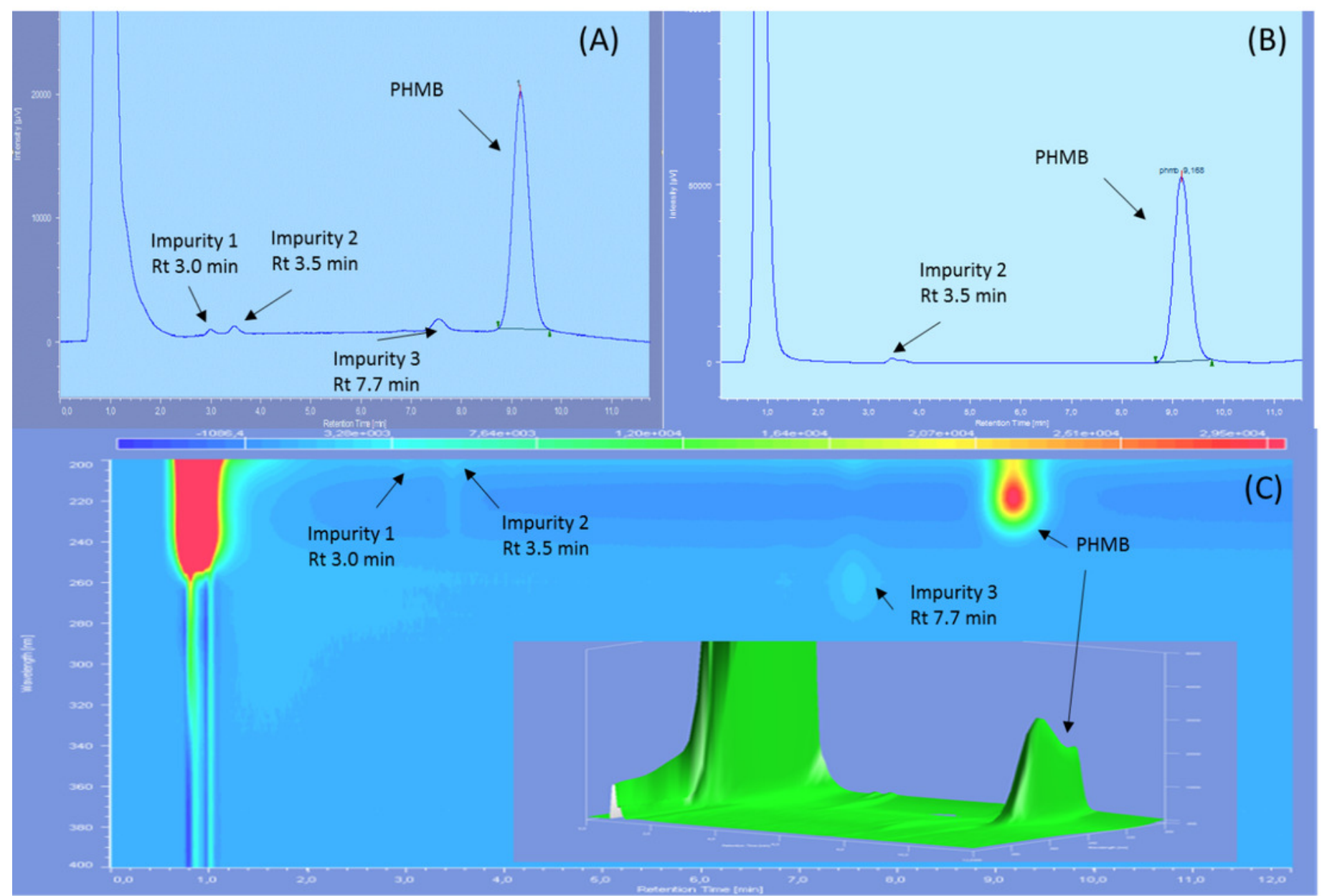




\section{Figure 2}

Screening with diode array detector of $0.2 \mathrm{mg} / \mathrm{mL}$ solution of PHMB after acid (A), alkaline (B), thermal (C) and oxidative (D) degradation.

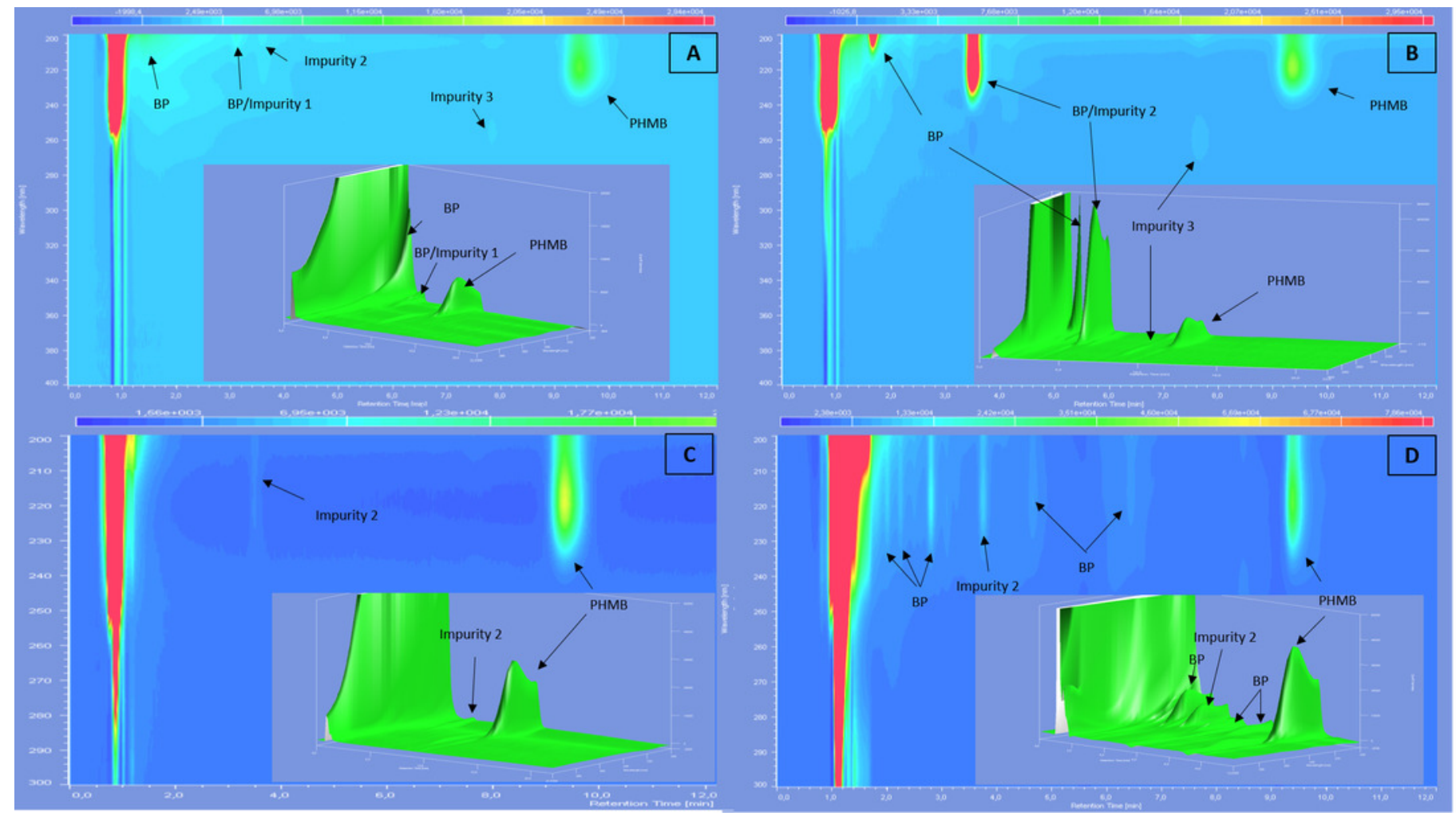


Figure 3

Relative retention times and relative intensity of all detected impurities and breakdown products function of the degradation conditions at $220 \mathrm{~nm} . *$ at $200 \mathrm{~nm}$

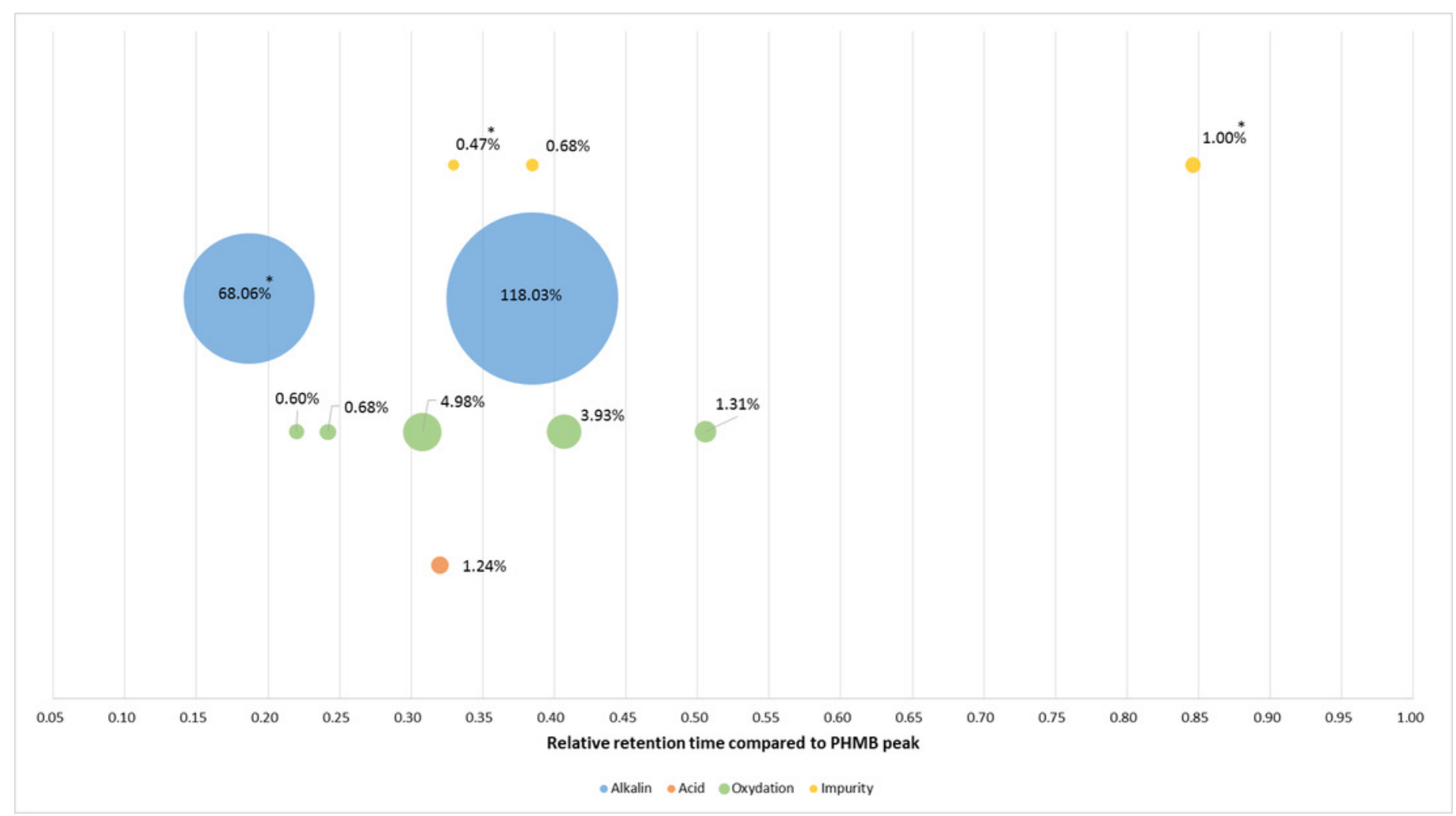




\section{Figure 4}

Chromatogram of PHMB solution in GS bottles at $25^{\circ} \mathrm{C}$ at day 0 (blue) and day 90 (red) in wavelength of $200 \mathrm{~nm}(\mathrm{~A}), 220 \mathrm{~nm}$ (B) and diode array detector screening (C)

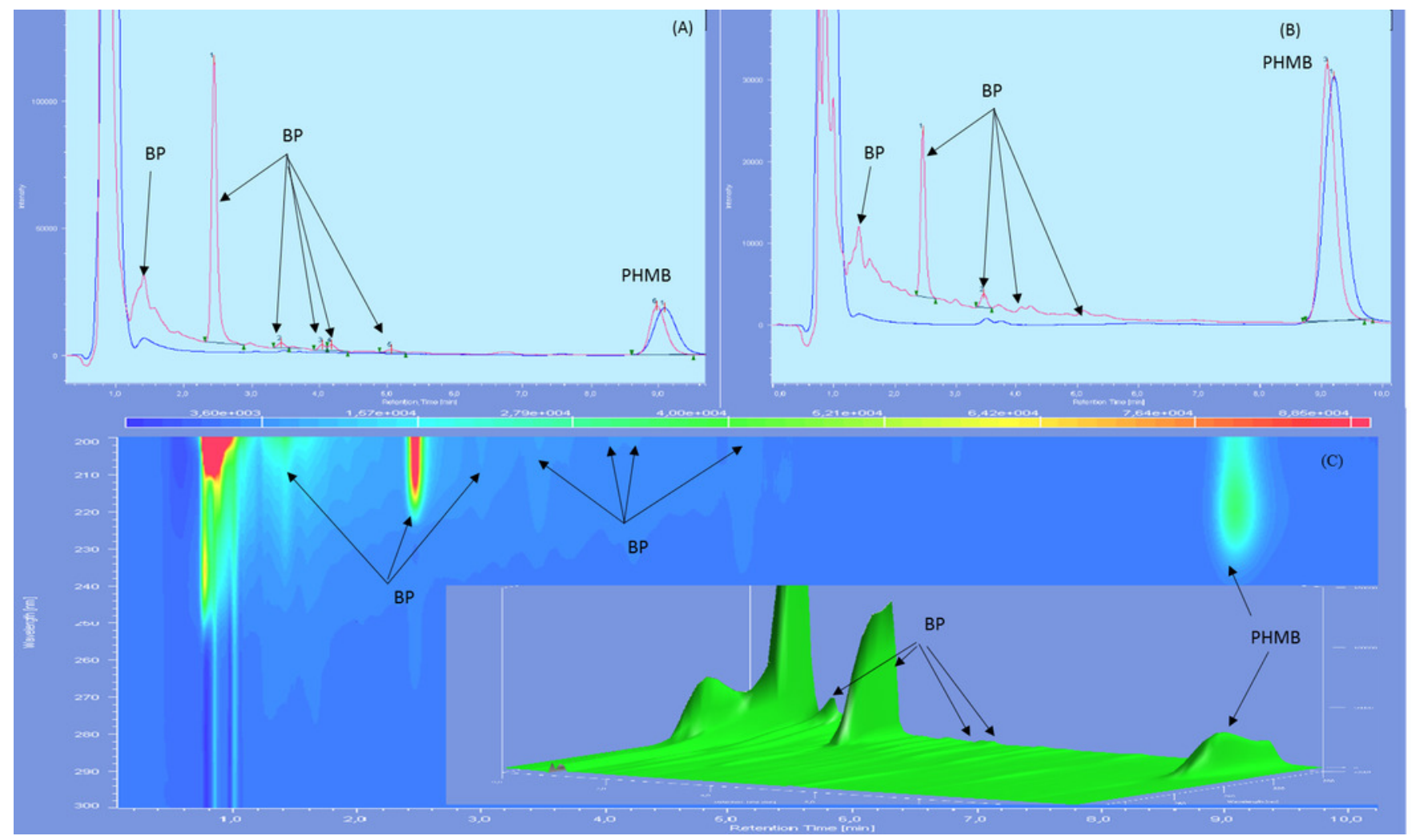




\section{Figure 5}

Chromatograms of $0.2 \mathrm{mg} / \mathrm{ml}$ PHMB solution in GS-LDPE bottle after 30 and 90 days storage at $5{ }^{\circ} \mathrm{C}$, viewed with $280 \mathrm{~nm}$ (PHMB not detectable at this wavelength) (A) and diode array detector screening (B).

BP: Breakdown Products

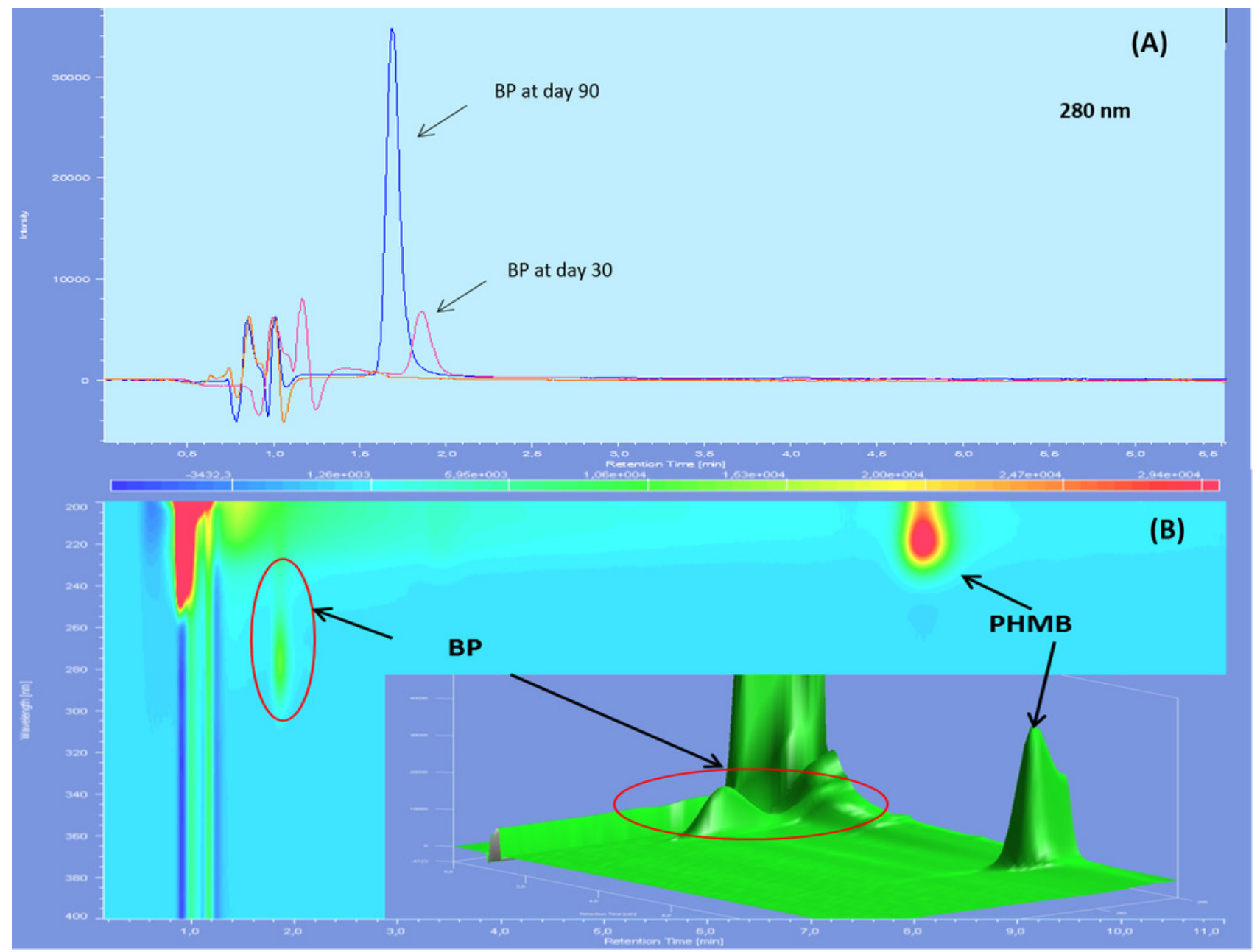


Figure 6

$\mathrm{pH}$ evolution in PHMB $0.2 \mathrm{mg} / \mathrm{mL}$ solution during 90 days (mean $\pm \mathrm{SD}, \mathrm{n}=3$ ). Straight red lines indicate initial $\mathrm{pH} \pm 1$ unit.

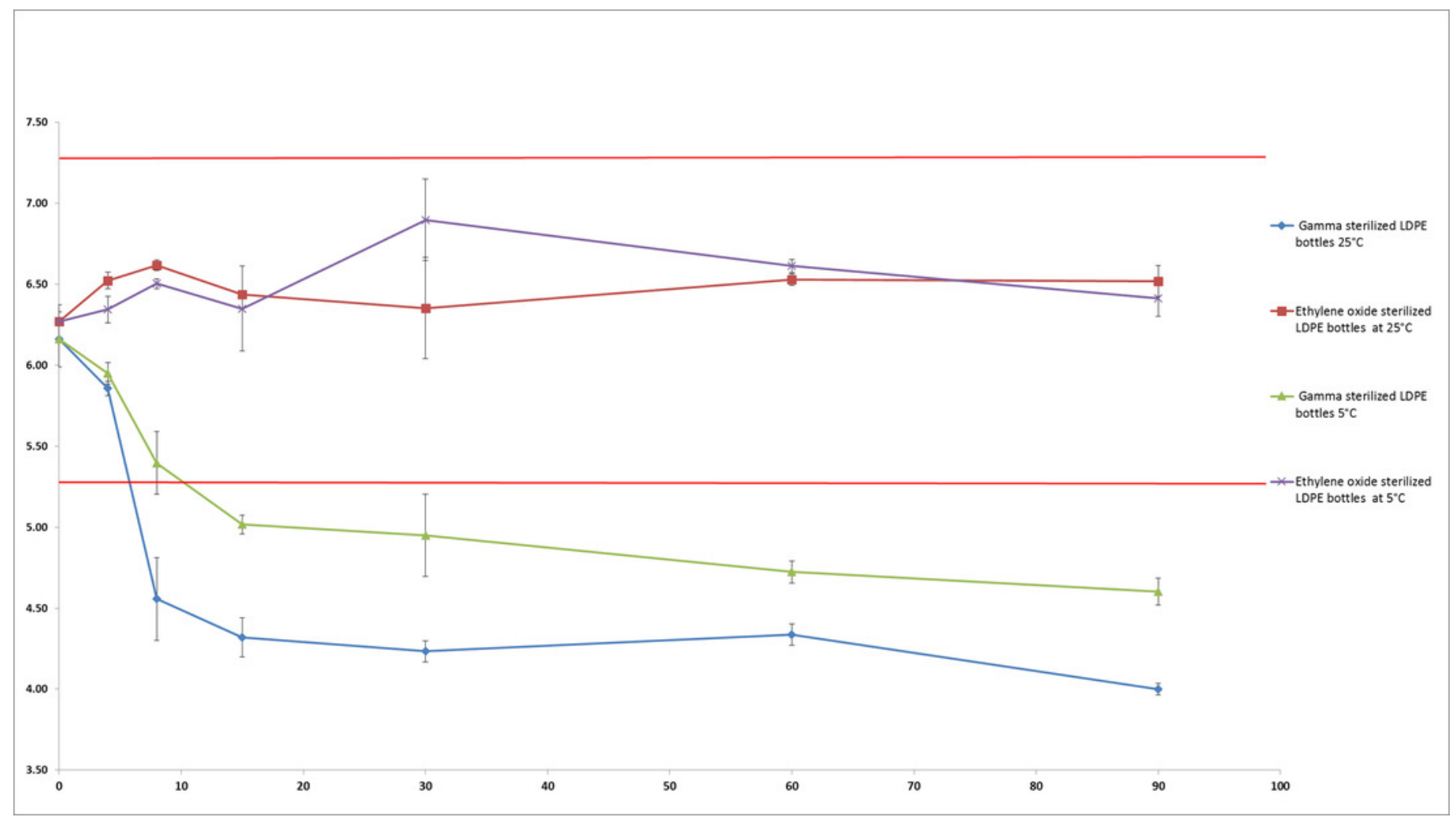


Figure 7

$\mathrm{pH}$ monitoring of $0.9 \% \mathrm{NaCl}$ in polypropylene, colored gamma sterilized, colored nonsterilized and non-colored non-sterilized low density polyethylenebottles during 30 days.

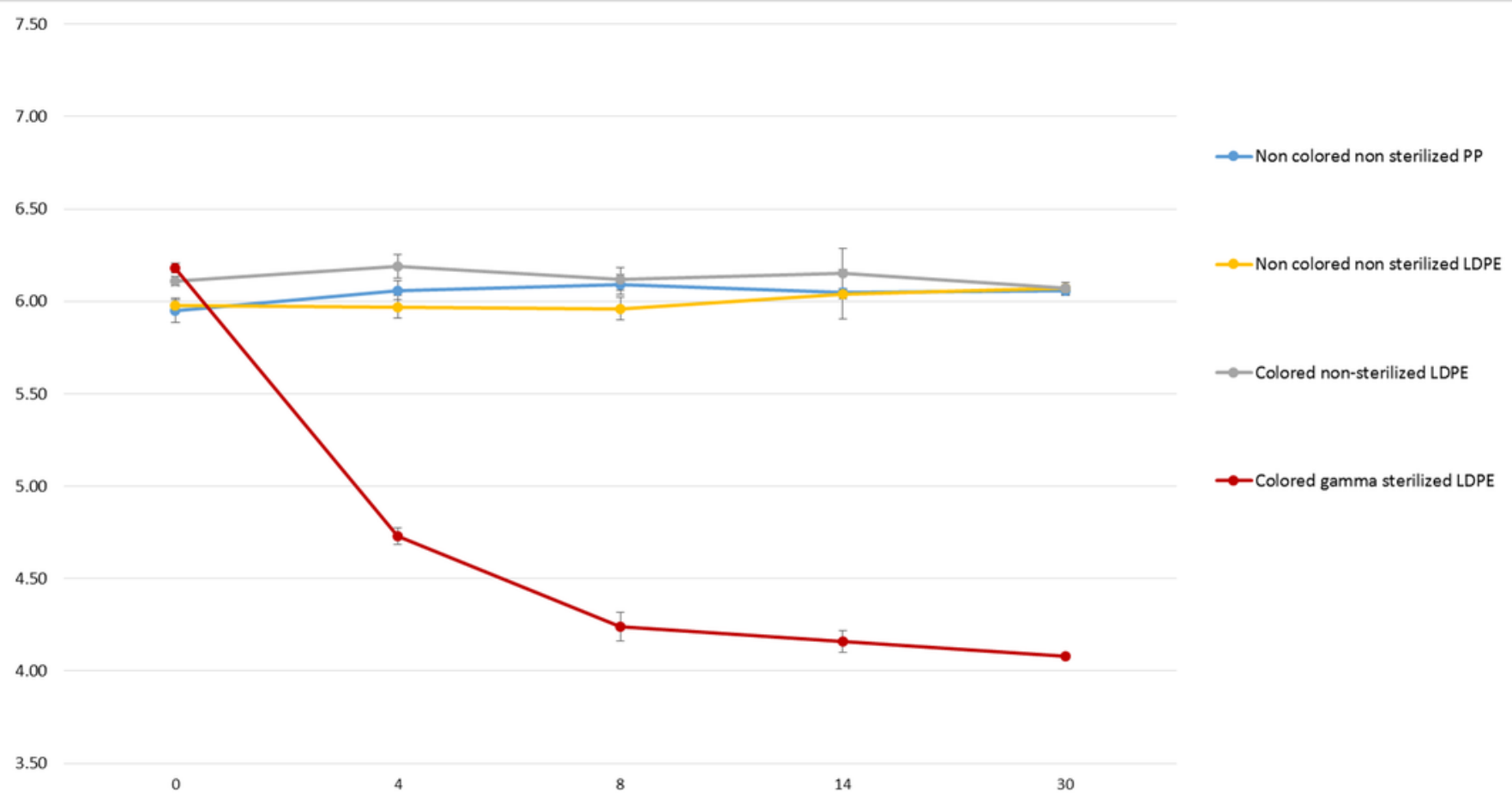




\section{Table $\mathbf{1}$ (on next page)}

Evolution of PHMB concentration for each storage condition and kind of bottle in unopened eyedroppers (mean \pm confidence interval, $n=3$ ). 
Kind of bottle and storage temperature

\section{Initial concentration at $D$ s}

$\mathbf{0}=\mathbf{1 0 0} \%$

(mg/mL)

(mean \pm IC $95 \%$ )
\% of initial T0 measurement (mean \pm CI 95\%)
Day 4

$0.204 \pm 0.002$

$\frac{99.8 \pm 3.19}{102.03 \pm 4.48}$

$98.8 \pm 6.55$
$98.94 \pm 1.54$

$98.44 \pm 5.2$

$99.85 \pm 4.90$

Day 15

Day 30

Day 60

Day 90

EOS-LDPE $25^{\circ} \mathrm{C}$

GS-LDPE

$\begin{array}{cc}5^{\circ} \mathrm{C} & 0.201 \pm 0.002\end{array}$

\begin{tabular}{cc}
$101.45 \pm 10.99$ & $104.5 \pm 0.75$ \\
\hline $100.83 \pm 7.63$ & $99.55 \pm 4.32$
\end{tabular}

$103.37 \pm 8.9$

$102.92 \pm 3.46$

$97.55 \pm 15.43$

$97.51 \pm 11.06$

$103.91 \pm 7.27$
$101.21 \pm 7.08$

$97.61 \pm 13.37$

$99.85 \pm 4.63$

$96.42 \pm 3.9$
$97.58 \pm 7.7$ 
Table 2 (on next page)

Evolution of PHMB concentration (\% of initial concentration) in drops for each storage condition and kind of bottle in in-use condition during 10 hours, pooled from 10 bottles $(n=1)$. * Not determined 


\begin{tabular}{|c|c|c|c|c|}
\hline \multirow{2}{*}{$\begin{array}{c}\text { Initial } \\
\text { concentration } \\
(\mathrm{mg} / \mathrm{mL}) \\
\end{array}$} & \multicolumn{2}{|c|}{ GS-LDPE } & \multicolumn{2}{|c|}{ EOS-LDPE } \\
\hline & \multicolumn{2}{|c|}{0.201} & \multicolumn{2}{|c|}{0.204} \\
\hline & \multicolumn{4}{|c|}{ Pourcentage of initial concentration } \\
\hline Hours & $25^{\circ} \mathrm{C}$ & $5^{\circ} \mathrm{C}$ & $25^{\circ} \mathrm{C}$ & $5^{\circ} \mathrm{C}$ \\
\hline 0 & $99.3 \%$ & $98.4 \%$ & $103.9 \%$ & $103.9 \%$ \\
\hline 1 & $104.2 \%$ & $103.9 \%$ & $*$ & $105.2 \%$ \\
\hline 2 & $99.7 \%$ & $103.6 \%$ & $101.3 \%$ & $105.1 \%$ \\
\hline 3 & $96.3 \%$ & $100.0 \%$ & $101.6 \%$ & $98.0 \%$ \\
\hline 5 & $105.9 \%$ & $105.7 \%$ & $105.7 \%$ & $100.1 \%$ \\
\hline 6 & $98.1 \%$ & $104.2 \%$ & $99.5 \%$ & $102.2 \%$ \\
\hline 7 & $99.7 \%$ & $104.4 \%$ & $103.1 \%$ & $104.8 \%$ \\
\hline 8 & $101.8 \%$ & $102.6 \%$ & $103.4 \%$ & $105.0 \%$ \\
\hline 9 & $102.7 \%$ & $102.9 \%$ & $101.3 \%$ & $101.9 \%$ \\
\hline 10 & $103.3 \%$ & $102.7 \%$ & $103.6 \%$ & $104.4 \%$ \\
\hline
\end{tabular}

